\title{
Peran Guru dalam Pencegahan Bullying di PAUD
}

\author{
Andini Dwi Arumsari, S.Psi, M.Psi ${ }^{1}$ \\ Dedi Setyawan, S.Pd.I \\ ${ }^{1}$ Program Studi PG PAUD FKIP Universitas Narotama Surabaya \\ ${ }^{2}$ Magister Teknologi Pendidikan Universitas Dr. Soetomo Surabaya
}

\begin{abstract}
Abstrak
Bullying merupakan perilaku sosial yang seringkali terjadi di sekolah. Bullying melibatkan siswa sebagai pelaku, korban, dan bystander. Perilaku bullying juga memberikan beberapa dampak negatif, baik untuk korban maupun untuk pelaku. Jika tindak bullying terjadi di Pendidikan Anak Usia Dini (PAUD), maka peran seorang guru sangat dibutuhkan agar guru mampu mengenali, mengidentifikasi, dan menanganinya. Penelitian ini bertujuan untuk mengetahui pentingnya peran seorang guru dalam mencegah terjadinya bullying di Pendidikan Anak Usia Dini (PAUD). Penelitian ini menggunakan metode tinjauan pustaka yang terkait dengan bullying yang terjadi di PAUD, dan wawancara yang dilakukan pada guru Taman Kanak-Kanak (TK). Hasil penelitian ini menunjukkan bahwa guru mengetahui tindak kekerasan apa saja yang dilakukan oleh peserta didiknya, namun guru belum mengetahui bahwa tindak kekerasan tersebut merupakan tandatanda terjadinya bullying yang dilakukan anak usia dini. Perilaku bullying yang terjadi pada anak usia dini merupakan tanda-tanda terjadinya peristiwa bullying dan kenakalan remaja di masa yang akan datang. Untuk itu, guru berperan penting dalam mencegah tindak bullying pada anak usia dini, agar perilaku bullying tidak berlanjut sampai ke usia remaja.
\end{abstract}

Kata kunci: peran guru PAUD, Bullying, anak usia dini,

\begin{abstract}
Bullying is social behaviour that commonly happened in educational environment. Bullying involves student as the actor, victim, and bystander. This behaviour stimulates various negative impacts not only for victim but also the actor. When bullying happens in early childhood education, educator plays essential role to recognise, identify, and prevent it. The present study aims to elaborate the important of educator role in preventing bullying that may occur in early childhood education. The present study uses literature review in order to gain information that are related to bullying in early childhood education. moreover, the present study also conducts
\end{abstract}


interview with various educators to gain valid data regarding this behaviour. The present study shows that educators recognise violent acts that are conducted by their student but unfortunately they are not able to identify whether those actions can be determined as bullying toward early childhood children. Moreover, this violent action is a stimulus which can lead a children in conducting juvenile delinquency in the near future for the actor. Therefore, early childhood educator holds essential role in preventing bullying acts for early childhood children in order to prevent this behaviour becomes a habit.

Keywords: Early Childhood Educator Role, Bullying, Early Childhood Children

\section{PENDAHULUAN}

Pendidikan anak usia dini merupakan pendidikan yang sangat penting dalam perkembangan seorang manusia. Selama mengikuti pendidikan di usia dini tersebut, seorang anak diajarkan untuk dapat mengembangkan berbagai macam kemampuan yang seharusnya dimiliki oleh manusia. Kemampuan-kemampuan tersebut misalnya kemampuan motorik, kemampuan kognitif, kemampuan bahasa, dan kemampuan sosial.

Salah satu kemampuan dalam perkembangan anak yang cukup penting adalah kemampuan sosialnya, karena di dalam proses belajarnya anak seringkali bermain dengan lingkungan sosialnya. Di dalam mengembangkan kemampuan sosialnya, anak diajarkan untuk dapat berinteraksi, bermain, dan bersosialisasi dengan teman sebayanya. Berbagai pengalaman sosial yang dialami anak bisa membuat perkembangan sosialnya lebih berkembang, memperkuat mental dan ketahanan seorang anak ketika menghadapi suatu masalah.

Di dalam lingkungan sosialnya tersebut, sering kali kita temui anak-anak bermain dengan menggunakan kekerasan ketika sedang berinteraksi dengan temannya. Kekerasan yang muncul, seperti kekerasan fisik maupun non fisik. Kekerasan fisik yang terjadi misalnya memukul, menendang, menyemburkan ludah, dll. Kekerasan non fisik seperti mengejek berteriak ke temannya, dll. Namun pada dasarnya, setiap anak berhak untuk merasakan keamanan, kedamaian dan kebahagiaan. Namun, banyak anak usia dini mengalami berbagai bentuk kekerasan. Kekerasan pada anak usia dini merupakan tanda-tanda perilaku bullying di masa depan. Ken Rigby mendefinisikan bullying itu sendiri dengan arti suatu perilaku negative yang dilakukan berulang-ulang, dengan maksud menyebabkan ketidaksenangan atau menyakitkan yang 
dilakukan oleh orang lain (satu atau sekelompok orang) secara langsung terhadap seseorang yang tidak mampu melawan (Beane, 2008).

Perilaku bullying seringkali diartikan sebagai bagian dari perilaku agresif. Menurut Olweus (2008) karakteristik bullying adalah adanya perilaku negatif yang dilakukan secara berulang kali (baik secara fisik, verbal maupun psikologis) diarahkan secara langsung kepada korban yang akan menyakiti korban, sepanjang waktu, dan melibatkan adanya perbedaan kekuatan antara korban dan pelaku (Olweus, 2005). Selain itu, bullying adalah sebuah perilaku sosial yang seringkali melibatkan beberapa anak, terjadi berulang kali, dilakukan untuk memenuhi kebutuhan anak yang berkuasa di lingkungan sosialnya, dan menjadikan bahaya bagi anak yang tidak mampu untuk menghentikannya (Robinson \& Maines, 2008).

Bullying seringkali dilakukan secara berkelanjutan dan dalam jangka waktu yang cukup lama, sehingga korban bullying terus-menerus berada dalam keadaan cemas dan terintimidasi. Bullying berbeda dengan perilaku agresif lain yang dilakukan hanya satu kali kesempatan dan dalam jangka waktu pendek. Perilaku agresi tidak akan diartikan sebagai perilaku bullying kecuali ada perasaan takut yang berkelanjutan pada korban. Olweus (Safe School Centre, 1999) mengatakan ada beberapa hal yang membedakan perilaku bullying dengan bentuk perilaku agresif lainnya, yaitu (1) kekuatan: anak-anak yang disebut sebagai pelaku berperilaku bullying karena ukuran fisik serta status dalam teman sebayanya, dan dengan mendapatkan dukungan dari teman sebayanya, (2) frekuensi: perilaku bullying tidak berasal dari tindakan yang acak. Bullying selalu ditandai dengan adanya kekerasan yang dilakukan pelaku bullying dan dilakukan berulang-ulang, (3) adanya niat untuk menyakiti: anak-anak yang menjadi pelaku bullying seringkali melakukan tindakan tersebut untuk membahayakan anak lain, baik secara fisik ataupun emosional.

Perilaku bullying dibagi menjadi dua kategori, bullying yang dilakukan secara langsung dan tidak langsung (Smith et.al, 2005). Bullying yang dilakukan secara langsung termasuk pada perilaku verbal dan non verbal. Perilaku verbal pada bullying seperti mengejek, berteriak, dll. Mengancam melalui telepon adalah bentuk baru dari bullying verbal (Porter, 2007). Perilaku non verbal pada bullying seperti memukul, menendang, dll. Bullying yang dilakukan secara tidak langsung lebih sulit untuk diobservasi, seperti menyebarkan gosip, mengucilkan seseorang dari 
kelompok mereka, dll. Bullying yang dilakukan secara tidak langsung akan sulit untuk dideteksi oleh pihak sekolah.

Menurut Sullivan (2000) bullying melibatkan 3 hal: pelaku, korban, dan orang yang melihat perilaku bullying (bystanders). Pelaku adalah seseorang atau sekumpulan orang yang mempunyai tingkah laku sama dan mempunyai kebutuhan yang sama. Kebutuhan yang dimaksud adalah kebutuhan melakukan sesuatu yang membuat senang pelaku, mendapatkan status sosial tertentu atau keuntungan materi, dan tidak memikirkan kebutuhan dan hak orang lain (Robinson \& Maines, 2008). Karakter dari pelaku bullying seperti seseorang yang impulsive, memiliki keinginan yang besar untuk mendominasi anak lainnya, mempunyai sebuah kelompok yang memberikan dukungan, dan tidak mempunyai rasa empati terhadap korban bullying (Cairns, Cairns, Neekerman, Gest, \& Gariepy, 1988; Olweus, 1993; Pulkkinen \& Tremblay, 1992, dalam Wong, 2004).

Korban bullying sering disebut dengan victim. Korban bullying merupakan seseorang atau sekelompok orang yang sering disakiti oleh perilaku orang lain dan tidak mempunyai kekuatan, kemampuan, atau kemungkinan untuk membalas perilaku tersebut atau menghentikan perilaku yang menyakiti tersebut (Robinson \& Maines, 2008). Korban bullying di sekolah secara psikologis ditunjukkan sebagai seorang anak yang introvert, mempunyai harga diri rendah, dan kurang mempunyai keterampilan sosial, khususnya dalam hal keasertifan (Rigby, 2003). Korban tidak memiliki kekuatan untuk melawan, merasa disakiti, takut untuk bertemu dengan pelaku, dan mempunyai keinginanan untuk berhenti disakiti oleh pelaku (Robinson \& Maines, 2008). Biasanya korban bullying tidak mengungkapkan kepada guru atau keluarganya mengenai perilaku bullying yang mereka alami. Hal tersebut terjadi karena para korban takut akan terjadinya pembalasan atau mereka merasa bisa menyelesaikan masalahnya sendiri.

Orang yang melihat perilaku bullying disebut dengan bystanders. Bystanders adalah seseorang yang menjadi saksi perilaku bullying. Bystander seringkali melakukan sesuatu tetapi ada juga yang tidak melakukan apapun untuk menghentikan bullying (Entenman, Murnen, \& Hendricks, 2005). Sebuah penelitian menunjukkan bahwa bystanders biasanya akan mendukung korban, akan mengabaikan apa yang sedang terjadi, akan mendukung pelaku, atau akan mengatakan peristiwa bullying pada guru (Rigby \& Johnson, 2005). 
Banyak kasus bullying yang sering menimpa anak usia dini, baik di rumah dan di sekolah. Pada anak usia dini yang berada di Taman Kanak-kanak (TK), pernah mengalami berbagai bentuk perlakuan tidak menyenangkan dari anak lain yang lebih tua atau yang lebih kuat. Berdasarkan hasil wawancara kepada guru TK di daerah Kecamatan Jetis Bantul, ditemukan fakta bahwa adanya tindakan bullying. Bentuk bullying yang terjadi di anak bermacam-macam, namun yang sering terjadi adalah bullying dalam bentuk verbal. Contohnya adalah memanggil dengan julukan yang tidak baik, mengejek, mengolok-olok, nyuraki, dan bullying dalam bentuk verbal lainnya. Selain itu, bullying juga terjadi dalam bentuk fisik, seperti memukul teman, menendang, dan mencubit.

Dari hasil penelitian yang telah dilakukan perilaku bullying memberikan beberapa dampak negative, baik untuk korban maupun untuk pelaku (Rejeki, 2016). Dampak negative untuk korban bullying di sekolah, misalnya adalah anak yang menjadi korban tersebut akan merasa bahwa sekolah merupakan tempat yang tidak nyaman baginya. Ketakutan yang dialaminya tersebut, akan memunculkan perasaan cemas yang bisa saja mengarah ke depresi dan anak yang menjadi korban akan mempunyai harga diri yang rendah. Hal tersebut membuat dia seringkali menolak untuk pergi ke sekolah. Dampak negatif bagi pelaku bullying adalah anak akan terbentuk karakter yang selalu menang dan berkuasa terhadap teman-temannya, terutama temanteman yang lebih lemah dari pada dia. Selain itu, jika perilaku bullying ini terjadi pada anak usia dini, akan berdampak buruk pada perkembangan-perkembangan selanjutnya.

Jika tindak bullying terjadi di dalam Pendidikan Anak Usia Dini, maka sangat dibutuhkan peran seorang guru untuk dapat mengenali, mengidentifikasi, dan menanganinya. penelitian yang dilakukan oleh Nugroho (2009) mengenai bullying menunjukkan bahwa cara penanganan yang dilakukan oleh guru di sekolah pun terbatas pada pemanggilan pelaku dan memberikan nasehat kepada pelaku saja. Guru seharusnya mampu mengenali perilaku bullying, sehingga diharapkan guru mampu mencegah perilaku bullying tersebut dan membentuk karakter yang baik agar anak mampu melalui tahapan perkembangan selanjutnya dengan baik.

Guru sebagai pendamping dan pembimbing anak ketika berada di sekolah membutuhkan pengetahuan tentang psikologi anak, terutama anak usia dini. Pengetahuan tentang psikologi tersebut akan sangat berguna untuk menangani peristiwa bullying yang sedang dialami oleh siswanya. Rata-rata guru PAUD di Kecamatan Kedung Jepara Jawa Tengah bukanlah merupakan 
lulusan dari Pendidikan Guru TK atau PAUD (Rejeki, 2016). Dari hasil wawancara, didapatkan data bahwa banyak dari guru PAUD yang berasal dari berbagai background pendidikan, yaitu pendidikan matematika, Seni, Bahasa, dll. Walapun berasal dari berbagai latar belakang pendidikan, guru harus mampu memahami setiap permasalahan yang dialami oleh siswanya, salah satunya adalah peristiwa bullying yang terjadi di siswa.

Guru menjadi orang yang pertama kali yang seharusnya menangani kasus bullying. Hal tersebut dikarenakan guru adalah seseorang yang berinteraksi dengan murid-muridnya lebih lama daripada staf sekolah lainnya di sekolah. Guru di sekolah mempunyai peran yang cukup penting untuk memberikan pengetahuan tentang bullying dan membuat suatu kebijakan yang tegas dan konsisten terhadap perilaku ini. Selain itu, guru juga mempunyai peran penting untuk dapat memunculkan dukungan yang baik terhadaop pelaku maupun korban bullying (Siswati \& Widayanti, 2009). Oleh karena itu, sebelum guru menangani perilaku bullying, guru harus memahami perilaku bullying terselbih dahulu, memahami ciri-ciri pelaku dan korban bullying, dan memahami bagaimana cara memberikan instruksi kepada siswa untuk menghadapi peristiwa bullying (Rock, Hammond, \& Rasmussen, 2004).

\section{METODOLOGI}

Di dalam penelitian ini, ada dua pendekatan yang digunakan sebagai metodologi penelitian. Metodologi pertama yang digunakan adalah tinjauan pustaka. Studi pustaka yang dilakukan adalah dengan menggunakan teori-teori bullying terutama yang terjadi pada anak usia dini, Selain itu, peneliti juga melakukan wawancara kepada guru atau pendidik yang mengajar di Pendidikan Anak Usia Dini. Anak usia dini adalah anak yang berumur 0-6 tahun. Untuk itu, wawancara dilakukan pada guru yang mengajar di Taman Kanak-Kanan (TK). Dengan melakukan wawancara, diharapkan mendapatkan data yang lebih lengkap dan mendalam mengenai tanda-tanda terjadinya bullying pada anak usia dini.

\section{PEMBAHASAN}

Peristiwa Bullying bukan hanya terjadi dikarenakan adanya interaksi yang sederhana antara pelaku bullying dan korban saja, namun bisa saja terjadi pada kelompok teman yang mempunyai usia yang sama, keluarga, dan sekolahnya. Hasil penelitian menunjukkan bahwa 
keadaan di sekolah yang negatif merupakan salah satu faktor terjadinya bullying. Keadaan sekolah yang negatif tersebut mampu menimbulkan perilaku bullying di lingkungan sekolah. Hal tersebut dikarenakan, sekolah hanya menekankan pada hasil akademiknya saja. Sekolah kurang memperhatikan pada nilai-nilai diluar akademiknya. Akhirnya, membuat siswa dapat dengan mudah melampiaskan emosinya pada teman-temannya atau benda-benda di sekitarnya. Sehingga, anak-anak kurang mempunyai kemampuan untuk menyelesaikan masalahnya yang sedang mereka alami. Ejekan yang ringan dari temannya mampu berubah menjadi pertengkaran yang berakibat pada munculnya perilaku agresif pada anak (Wong, 2004).

Beberapa hasil dari penelitian yang telah dilakukan, memberikan hasil bahwa antara hubungan anak yang mempunyai hubungan yang tidak baik dengan teman sebayanya, hubungan yang tidak baik dengan guru-gurunya, dan mempunyai kemampuan akademik kurang, lebih memungkinkan untuk melakukan perilaku bullying dan sering terlibat dalam tindak kriminal di sekolah (Wong 2004). Selain itu, anak-anak tersebut juga berpotensi besar untuk melakukan kenakalan remaja di masa depan (Smith et.al, 2005). Kurang adanya aturan dan pengawasan pada aktivitas anak merupakan salah satu faktor yang membuat anak terlibat dalam bullying dan tindak kriminal di sekolah (Wong, 2004). Bullying adalah perilaku sosial yang berbahaya karena dapat memberikan dampak traumatic yang dapat mempengaruhi perilaku anak-anak pada tahap perkembangan selanjutnya (Arumsari, 2017). Anak yang di usia dininya terindikasi dan terlibat dengan peristiwa bullying berpotensi untuk menjadi pelaku kenakalan remaja, tindakan kekerasan, serta terjebak dalam tindakan criminal.

Untuk itu, perilaku bullying harus segera ditangani sedini mungkin, dengan cara yang tepat. Penanganan yang tepat tersebut, bisa saja diberikan kepada pelaku, korban, maupun teman-teman yang lain yang menyaksikan perilaku bullying tersebut. Penanganan yang dilakukan di sekolah sebaiknya dilakukan oleh para guru. Oleh karena itu, sebelum perilaku bullying terjadi, guru perlu untuk mengetahui perihal bullying di sekolah sehingga guru mampu mencegah terjadinya bullying. Pencegahan bullying di sekolah tersebut dimulai sejak anak-anak berada di Pendidikan Anak Usia Dini (PAUD).

Dari hasil wawancara yang dilakukan oleh peneliti, guru di Taman Kanak-Kanak (TK) mengatakan bahwa tanda-tanda bullying sudah tampak di anak usia dini. Tanda-tanda munculnya bullying tersebut biasanya dalam bentuk verbal dan non verbal. Bullying yang sering muncul 
dalam bentuk verbal misalnya memanggil seseorang anak dengan nama julukan, berteriak pada anak yang lebih muda umurnya, melaporkan perilaku temannya kepada gurunya dengan tujuan agar gurunya menegur temannya tersebut, dan lain-lain. Bullying yang sering muncul dalam bentuk non verbal misalnya menendang, memukul, mendorong temannya yang badannya lebih kecil, dan lain-lain.

Anak-anak yang menjadi korban bullying biasanya merasa malu, takut, dan tidak nyaman (Rejeki, 2016). Untuk itu, korban bullying ini harus diberikan pemahaman mengenai peristiwa bullying. Selain itu, dia harus dibekali dengan rasa percaya diri yang tinggi pada dirinya sendiri. Untuk meningkatkan rasa percaya dirinya tersebut guru dapat memusatkan perhatian pada hal yang menjadi kelebihan dan potensi yang dia miliki.

Perilaku yang dilakukan siswa Taman Kanak-Kanak (TK) tersebut merupakan tandatanda terjadinya bullying pada anak usia dini. Tanda-tanda peristiwa bullying tersebut jika tidak disadari dan diketahui oleh guru akan membuat dampak negative pada korban dan pelaku bullying di masa yang akan datang. Untuk mencegah terjadinya bullying di Taman Kanak-Kanak (TK), guru sebaiknya:

a. Melatih siswa untuk lebih asertif

Sikap asertif dibutuhkan seorang anak untuk dapat mengungkapkan apa yang ada di pikirannya dan perasaanya dengan sebenar-benarnya tanpa harus menyinggung perasaan anak lainnya

b. Mengawasi siswa selama di sekolah

Pengawasan pada anak usia dini di sekolah merupakan salah satu tindakan pencegahan agar perilaku bullying tidak terjadi pada siswa Taman Kanak-Kanak (TK). Selain mengawasi, guru hendaknya juga memberikan pemahaman agar selalu memberi tahukan kepada guru terkait keberadaannya di sekolah, dengan siapa mereka bermain, dan berhati-hati dengan orang yang tidak dikenal.

c. Memberikan materi pembelajaran pada anak yang berkaitan dengan bullying melalui bermain

Pembelajaran mengenai bullying bisa diberikan dengan menggunakan cerita atau bermain di sekolah. Guru harus kreatif dalam memberikan pembelajaran tersebut. Cara tersebut dilakukan agar anak tertarik dengan materi yang diberikan. 


\section{d. Mengadakan kegiatan Parenting}

Komunikasi anatara guru dan orang tua harus terus terjalin selama anak bersekolah di sekolah tersebut. Salah satu cara komunikasi yang dapat dilakukan adalah dengan cara mengadakan parenting. Di dalam program parenting tersebut, orang tua perlu mengetahui gaya pengasuhan yang tepat pada anak, cara mengatasi permasalahan yang terjadi pada anak, dan seringkali orang tua tidak mengetahui dampak perilakunya terhadap perkembangan anak.

\section{KESIMPULAN}

Pencegahan bullying perlu dilakukan, terutama oleh guru. Hal tersebut dikarenakan, bullying seringkali terjadi di sekolah. Guru mempunyai peran penting dalam memahami, mencegah, dan menangani perilaku bullying. Guru perlu mempunyai metode yang terencana dalam mencegah bullying tersebut. Selain itu, pencegahan bullying juga harus dilakukan oleh guru dengan cara yang menyenangkan, misalnya melalui bermain dan bercerita. Karena pada anak usia dini (0-6 tahun), pembelajaran dapat diberikan melalui metode tersebut. Guru juga sebaiknya bekerja sama dengan orang tua dalam mencegah bullying pada anak.

\section{DAFTAR PUSTAKA}

Arumsari, Andini Dwi. (2017). Bullying pada Anak Usia Dini. Motoric, Vol. 1, No. 1.

Beane, Allan. L., (2008). Protect Your Child from Bullying: Expert Advice to Help You Recognize, Prevent, and Stop Bulliyng Before Your Child Gets Hurt. USA: Jossey-Bass.

Entenman, J., Murnen, T. J., \& Hendricks, C. (2005). Victims, Bullies, and Bystanders in K-3 Literature. International Reading Association (pp. 352-364).

Nugroho, S. (2009). Program Psikoedukasi untuk Meningkatkan Pengetahuan dan Keterampilan Guru dalam Menangani Bullying. Tesis. Magister Profesi Psikologi Universitas Gadjah Mada Jogjakarta. Tidak Diterbitkan.

Olweus, D. (1997). Bully / Victim Problems in School: Facts and Intervention. European Journal of Psychology of Education, XII (4), 495-510. 
Olweus, D. (2005). Bullying at School: What We Know and What We Can Do. Australia: Blackwell Publishing.

Porter, L. (2007). Student Behavior: Theory and Practice for Teachers, $3^{\text {rd }}$ Ed. Sydney: Allen and Uwin.

Rejeki, Sri. (2016). Pendidikan Psikologi Anak “Anti Bullying” pada Guru-Guru PAUD. Dimas, Vol. 16, no. 2, November 2016.

Rigby, K. (2003). Consequences of Bullying in School. Can J Psychiatry, 48 (9), 583-590.

Rigby, K., \& Johnson, B. (2005). Student Bystanders in Australian Schools. Pastoral Carein Education, 23 (2), 10-16.

Rock, E.A., Hammond, M., \& Rasmussen, S. (2004). School wide bullying prevention program for elementary students. http://www.haworthpress.com/web/JEA

Siswati, \& Widayanti, C. G. (2009). Fenomena Bullying di Sekolah Dasar di Semarang: Sebuah Studi Deskriptif. Jurnal Psikologi Undip, 5 (2).

Smith, J. D., Cousins, J. B., \& Stewart, R. (2005). Antibullying Interventions in Schools: Ingredients of Effective Programs. Canadian Journal of Education, 28 (4), 739-762.

Sullivan, K. (2000). School Bullying: Issues For Teachers. Issue, 23, 1-7.

The British Columbia Safe School Centre. (1999). Fokus on Bullying: A Prevention Program for Elementary School Communities.

Wong, D., S. (2004). School Bullying and Tackling Strategies in Hong Kong. International Journal of Offender Therapy and Comparative Criminology, 48, 537-553. 